\title{
Hydrogel bacterial cellulose: a path to improved materials for new eco-friendly textiles
}

\author{
Kamil Kamiński • Magdalena Jarosz • Joanna Grudzień · Justyna Pawlik • \\ Filip Zastawnik $\cdot$ Piotr Pandyra $\cdot$ Agata Maria Kołodziejczyk
}

Received: 10 April 2019/Accepted: 27 March 2020/Published online: 5 April 2020

(C) The Author(s) 2020

\begin{abstract}
In this paper, we present a novel, ecologically friendly technology for the synthesis and modification of kombucha-derived bacterial cellulose in order to produce textiles of desired physicochemical and mechanical properties. The procedure of manufacturing cellulose in the form of a stable hydrogel bacterial cellulose (HGBC) ensures the desired properties for the application of such a material, e.g., in the textile industry. Bacterial cellulose was obtained from a yeast/bacteria kombucha culture (a symbiotic consortium also known as "tea fungus" or SCOBY) that is easy and cheap to breed. The process of bacterial cellulose manufacturing and modification was optimized in order to obtain a maximum recovery of raw materials, minimal energy consumption and ensure the use of only natural and renewable resources. The
\end{abstract}

Electronic supplementary material The online version of this article (https://doi.org/10.1007/s10570-020-03128-3) contains supplementary material, which is available to authorized users.

K. Kamiński $(\bowtie) \cdot$ M. Jarosz · J. Grudzień Faculty of Chemistry, Jagiellonian University, Gronostajowa 2, 30-387 Kraków, Poland

e-mail: kaminski@chemia.uj.edu.pl

J. Pawlik

Faculty of Materials Science and Ceramics, AGH

University of Science and Technology, Mickiewicza Ave.

30, 30-059 Kraków, Poland obtained materials were characterized in terms of their wettability, mechanical properties, and flame resistance. Moreover, the morphology and composition of the materials were determined by using scanning electron microscopy and infrared spectroscopy, respectively. Additionally, it was proven that the HGBC materials might be used to manufacture various articles of clothing using commonly available sewing techniques, which are not adequate for nonmodified cellulose-based materials. Finally, the synthesized fabrics were used as wristbands and parts of T-shirts and tested on volunteers to determine a skinto-skin contact behaviour of the prepared fabrics. The reported results allow for confirming that the HGBC fabric may be used as a new textile and the proposed synthesis method is in accordance with the "green chemistry."

F. Zastawnik

Department of Design, Academy of Fine Arts, Smoleńsk

9, 31-107 Kraków, Poland

P. Pandyra

Department of Arts, Pedagogical University,

Podchorążych 2, 30-084 Kraków, Poland

A. M. Kołodziejczyk

Analog Astronaut Training Center, Morelowa 1F/4,

30-222 Kraków, Poland 


\section{Graphic abstract}

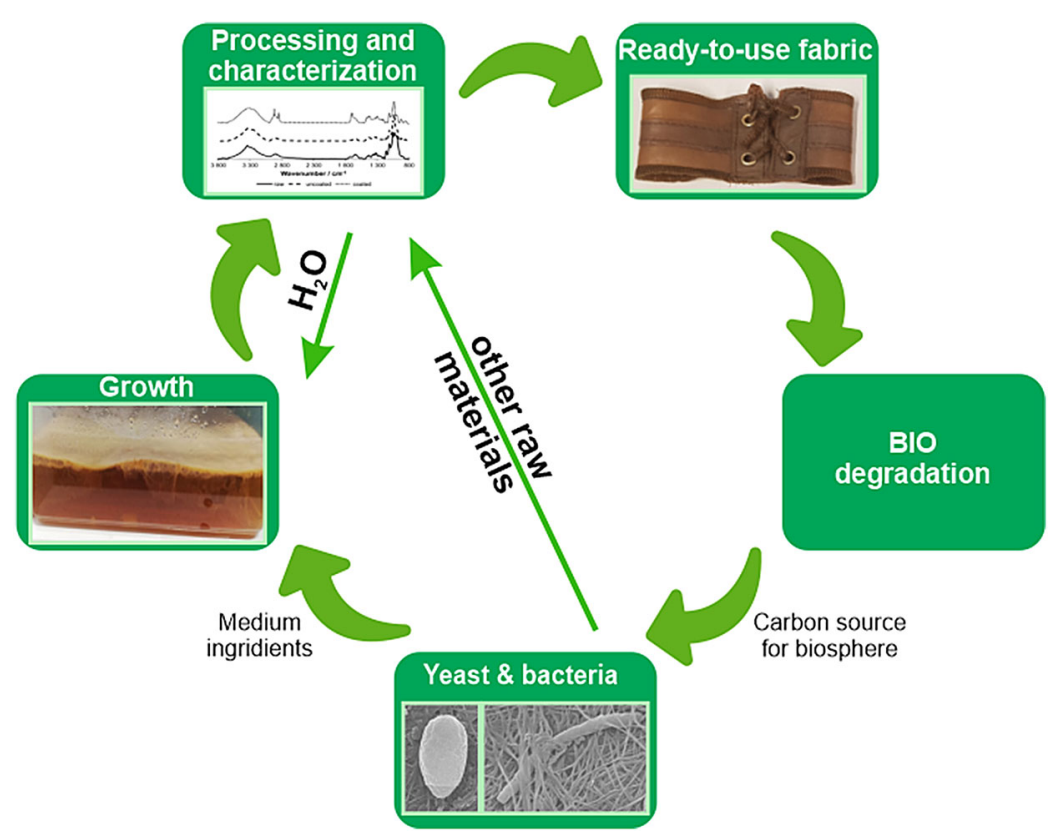

Keywords Bacterial cellulose $\cdot$ Hydrogel $\cdot$ Bacterial cellulose textile $\cdot$ Ecological fabrics

\section{Introduction}

One of the latest ecological problems when it comes to the use of clothes is the issue of biodegradability (Ahmed et al. 2018; Venter et al. 2016). Although items of clothing are used for a relatively long period, even by several consecutive users, they have to be regularly washed, which often results in the release of fibres into water (Carney Almroth et al. 2018). These fibres are mainly synthetic and as such are not biodegradable. In consequence, they are accumulated in aquatic organisms, which is devastating for the entire natural environment (Gago et al. 2018). Moreover, the dimensions of such fibres may reach even the nanoscale; thus, they cannot be easily filtered out and may pollute drinking water and also accumulate in human or animal organisms. In addition, the fashion industry has become one of the major contributors to water pollution, carbon dioxide emission and waste ( $\mathrm{Ng}$ and Wang 2016). Therefore, it is crucial to introduce ecologically friendly technologies into production of textiles and post production treatment of fabrics, to use an example.

What is even more interesting is that the issues of ecological clothing production and their biodegradability will soon affect not only the population living on our planet but also extra-terrestrial human colonies. The topic of clothes is a challenge for astronauts, and it will soon become crucial due to the increasing number of planned space travels. Textiles that are sent to space are not recycled under such conditions and cannot be washed, since "space washing machine" does not exist and, more importantly, water is highly limited in the outer space. The ideal solution would be clothing based on natural fabrics which would be obtained from sources that could be cultivated or grown even in the most challenging conditions, such as a spaceships. Under ideal conditions these materials could be biodegradable and the thus obtained biomass could be returned to the circulation by being re-used in bioreactors. To make it possible, it seems optimal to use natural fabrics which are almost always biodegradable (Béguin and Aubert 1994; Li et al. 2010; Podolich et al. 2017, 2019).

One of the most popular natural and biodegradable polymers is cellulose, the main constituent of wood and cotton (Dima et al. 2017; Keshk 2014; Sederavičiūte et al. 2019). It is abundantly present in the 
ecosystem, which makes it easy to obtain-by merely using various plants, as it is their main component. Unfortunately, cellulose obtained from wood has low crystallinity and is contaminated by other substances, like lignin and hemicellulose (Lima et al. 2017). What is more, in case of plant-derived cellulose, its treatment and processing require the use of harmful chemicals, and for the decontamination process, a lot of energy and water is needed.

Taking the above into consideration, a more environmentally friendly solution may be the use of bacteria-derived cellulose (BC) (Brown 1886). BC is a porous biopolymer possessing a knit-like structure that is produced in the fermentation process by various microorganisms, like bacteria of the genera Gluconobacter or Agrobacterium (Dima et al. 2017; ElSaied et al. 2004; Gao et al. 2019; Matthysse et al. 1995; Bandyopadhyay et al. 2018). The interest in bacteria-derived cellulose was aroused because of its exceptional physicochemical properties, like high crystallinity, high specific surface area, high elasticity, relatively high mechanical strength in the wet state, hydrophilicity and excellent biocompatibility (Abitbol et al. 2016; Campano et al. 2015; Habibi et al. 2010). Moreover, compared to plant-derived cellulose, cellulose of bacterial origin is of a high purity (free of hemicellulose, lignin, and pectin) (Reiniati et al. 2017). Finally, BC is a very convenient material when it comes to modifications in view of its applicability since it can be manufactured/grown in different shapes, processed to achieve enhanced properties and functionalized to gain new applications (Gao et al. 2019).

An interesting method of producing bacterial cellulose is the use of a symbiotic consortium of bacteria and yeast (SCOBY), widely known as kombucha (Dima et al. 2017). It was originally used to produce a non-alcoholic beverage by fermenting tea, and originated in ancient Manchuria around 2200 years ago. The kombucha solution is prepared with water, sugar, tea, and a kombucha culture (i.e., a symbiotic consortium known as 'tea fungus') in an open vessel at room temperature for 1-3 weeks, preferably in darkness (Nguyen et al. 2015). It consists of a multispecies bacterial component producing bacterial cellulose, and a multispecies fraction of yeasts. This symbiotic relationship is characterized by biological stability, resistance to contamination, and its applicable by-products: (1) bacterial cellulose, and
(2) probiotic brewing (Jayabalan et al. 2014). Bacteria and yeasts in kombucha are involved in various complementary metabolic activities that utilize substrates. Yeasts live on sucrose, which is hydrolysed to glucose and fructose by the enzyme invertase, and produce ethanol via glycolysis, with a preference for fructose as a substrate. On the other hand, acetic acid bacteria make use of glucose and ethanol to produce gluconic and acetic acids, respectively (Blanc 1996; Marsh et al. 2014). The synthesis of BC may be conducted either under static or dynamic conditions, what results in different forms of cellulose, i.e., threedimensional interconnected reticular pellicles and irregularly shaped, sphere-like cellulose particles, respectively (Azeredo et al. 2019; Costa et al. 2017).

Kombucha-derived bacterial cellulose (KBC) is not deprived of drawbacks (Araújo et al. 2015; Salmeia et al. 2016). The main disadvantage is the brown colour of the product which is a result of melanoidins from the Maillard reaction, and an unpleasant smell of the material due to the presence of difficult to remove fermentation products, mainly carboxylic acids (Wang et al. 2011). That is why various purification methods are employed in order to remove microorganisms and their metabolites from $\mathrm{BC}$, as well as to change its colour. The most popular method is the use of alkaline treatment. During such a procedure, $\mathrm{NaOH}$ solutions of differing concentrations, from 0.5 to $5 \mathrm{M}$, are used (Dima et al. 2017; Kulkarni et al. 2012; Lima et al. 2017; Bandyopadhyay et al. 2018; Sederavičiūtè et al. 2019). The alkaline purification method requires, however, the use of significant amounts of water and neutralizers to obtain materials with neutral $\mathrm{pH}$. Akkus et al. (2017) examined the effect of BC pretreatment in a mixture of polyethylene oxide and $\mathrm{NaOH}$ on degradation of the material that could be used as a soft tissue replacement. Another substance that may be applied for this purpose is sodium dodecyl sulfate (SDS) (Andrade et al. 2011). Interestingly, by applying various post-treatments, materials with diversified physicochemical properties may be obtained. For instance, Dima et al. examined the effects of atomization and microfluidization processes of $\mathrm{KBC}$ on the structure of cellulose fibres (Dima et al. 2017). As a result, dry and never-dried BC samples were obtained, respectively, having nano- and microfibers. Another drawback of $\mathrm{KBC}$ is the fact that in dry state it resembles paper. It is brittle and its mechanical properties are rather poor. Thus, modifications of its 
structure in order to enhance mechanical properties are also applied. For example, the addition of ligonosulfonates increases the crystallinity of $\mathrm{BC}$ and the Young's modulus due to the coarser cellulose ribbons (Keshk 2014). Nonetheless, there is still a need for a more eco-friendly technology of KBC production that will provide material with desired mechanical properties and simultaneously would not generate much waste.

Up to now, BC is starting to be used in medicine and dentistry (Fontana et al. 1990; Keshk 2014), the paper industry (Basta and El-Saied 2009; Hioki et al. 1995), food industry (Azeredo et al. 2019; Kuwana 1997) and recently, in the fashion industry (Domskiene et al. 2019; Ng 2017; Ng and Wang 2016). The latter is especially interesting since it is becoming a trend among various designers, like Suzan Lee, who launched a BioCouture, a project devoted to KBCbased fashion (https://www.launch.org/innovators/ suzanne-lee/). Also, Professor Christina Codgell from the UC Davis design is developing the production of a kombucha-based textile, constantly improving its properties (Codgell 2011). There is even an aspiring fashion house the designers of which mainly use such materials (http://www.kombuchacouture. $\mathrm{com} /$ ). Despite this fast-growing industry, there are still many technical and practical problems associated with manufacturing of $\mathrm{BC}$-based clothes that have to be addressed. One of such issues is the mechanical durability and comfort of use of such materials. The second issue, as mentioned above, is connect to contamination of the material with the components of the kombucha-growing medium, such as organic acids (responsible for the characteristic unpleasant smell) and microorganisms (possibly pathogenic for the compromised immune system).

In this work, we describe a new, environmentally friendly technology for the production of bacterial cellulose-based fabrics that will allow for overcoming the above mentioned challenges. Briefly, the idea focused on the improvement of flexibility and tensile strength of the material by introducing to the structure a water-retaining agent, namely glycerol, which would act as the molecular lubricant and result in the formation of a hydrogel structure of the material (HGBC-hydrogel bacterial cellulose). The surface of this material was also covered with stearic acid (cHGBC_coated hydrogel bacterial cellulose) to provide insulation from external water (a natural compound obtained from plants together with glycerol, e.g., in the production of biodiesel). The new material was characterized in terms of its physicochemical (also related to water absorption and modulating these parameters at the production stage) and mechanical properties and was used for the preparation of two types of clothing, which were then tested on volunteers. As highlighted at the beginning, one of the most important aspects of the proposed technology is the eco-friendliness, meaning minimalization of the generated waste, including reusable raw material. We believe that such an approach will be valuable form the viewpoint of ecology and industrial applicability of the proposed technology.

\section{Experimental}

Bacterial-derived cellulose preparation and its physicochemical behaviour

Kombucha (purchased at the farmers' market, regional sources in Stryszawa, Lesser Poland region) was grown in the medium prepared according to the protocol. In particular, $8 \mathrm{~g}$ of granulated black tea (Lipton Yellow Label) was brewed in $0.8 \mathrm{~L}$ of boiling water. The brewing continued for $5 \mathrm{~min}$, and then $96 \mathrm{~g}$ of sucrose dissolved in $1 \mathrm{~L}$ of boiling water was added. After cooling the mixture to room temperature, it was transferred to a rectangular plastic container (sterilized with $70 \%$ ethanol solution). A kombucha starter $(2 \times 2 \mathrm{~cm}$ cellulose sheet and $100 \mathrm{ml}$ of liquid containing yeast obtained from a smaller, 1-weekold culture prepared analogously) was introduced into the new media obtained as described above. The cultures were carried out under static conditions for 2 weeks to reach a kombucha-derived bacterial cellulose sheet (KBC) of approximately 1-2 cm thickness. The cultures were grown at the temperature of about $22{ }^{\circ} \mathrm{C}$.

After 2 weeks, the cellulose sheet was gently removed from the culture and immersed in distilled water (10 $\mathrm{ml}$ of water for each $1 \mathrm{~g}$ of wet cellulose) in order to remove the residual medium and, in particular, the remaining yeast. As prepared, the raw KBC material was used as a reference for further tests. In order to receive the starting Hydrogel Bacterial Cellulose (HGBC) material, the raw sheet was first frozen at $-15^{\circ} \mathrm{C}$ and then freeze-dried. The obtained 
material was placed in a glass container, and 6 or 12 $\mathrm{wt} \%$ aqueous glycerol solution $(100 \mathrm{ml}$ per each $1 \mathrm{~g}$ of lyophilized cellulose) was added. Then, it was autoclaved at $121{ }^{\circ} \mathrm{C}$ for $15 \mathrm{~min}$ using a steam autoclave (COMINOX Sterilclave $18 \mathrm{~S}$ ). After cooling down and rinsing the material with distilled water (in the same amount as previously), the lyophilization process was repeated. Finally, the stearic acid solution in ethanol (2.5 wt\%) was spread on the obtained fabrics using a brush. After applying the layer over the entire surface, the material was treated with a stream of hot air $\left(70-75^{\circ} \mathrm{C}\right)$ to remove ethanol and liquefy stearic acid. As a result, a homogeneous coverage of the material was obtained (hereafter referred as coated HGBC-cHGBC). It is also worth mentioning that during each step of the preparation, a procedure for recovery of the employed liquids was applied. In particular, the freeze-drying of the remaining solutions was employed. Additionally, chitosan material was used as a reference for wettability measurements. Details regarding its synthesis are described in Supplementary Material-Chitosan Synthesis Section. It should be mentioned that due to the instability (the leakage of water-containing glycerol), the material made using $12 \mathrm{wt} \%$ of glycerol was not used for any further tests except for swelling measurements.

The ultrastructure of the obtained materials was analysed by using a scanning electron microscope (SEM Phenom-World PRO, Pik Instruments, and for the picture in Fig. 1b: FE-SEM/EDS Hitachi S-4700 with a Noran System 7). In the case of the HGBC and cHGBC materials, the fixing procedure was limited only to drying the samples in air and then sputtering with a thin gold layer before imaging by using a
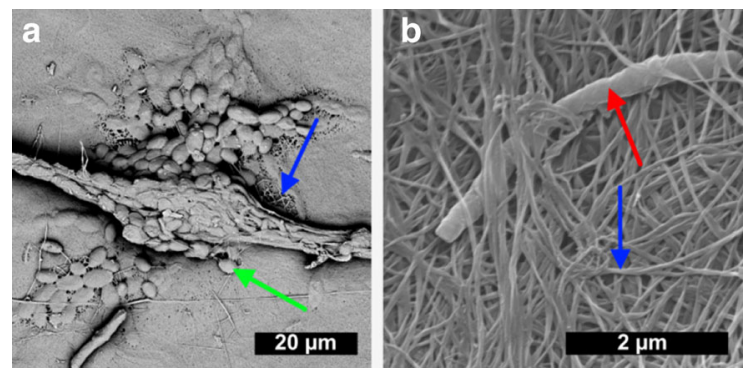

Fig. 1 SEM microphotographs of raw fragments of kombuchaderived cellulose $(\mathrm{KBC})$. a A view of a large fragment of the fabric with visible residual microorganisms: yeast (green arrow) and bacteria (red arrow) that are embedded in the cellulose fibres (blue arrows). b A close-up of cellulose fibres and a bacteria cell sputter-coater (Quorum Q150T S). In order to eliminate damaging the structure due to uncontrolled drying, a more complex procedure was assessed for the native structure, i.e., kombucha-derived cellulose straight from the culture (Chissoe et al. 1994; Fischer et al. 2012). It is particularly important since fresh cellulose fragments are unstable polymer hydrogels with a high content of unbound water. Therefore, the cross-sections of cellulose hydrogels were fixed in 3 $\mathrm{wt} \%$ glutaraldehyde in PBS for $1 \mathrm{~h}$, then dehydrated in growing concentrations of water-ethanol solutions (50, 60, 70, 80, 90, 96 and 100\%) for 10 min each. Finally, the samples were dried using hexamethyldisilazane (HMDS), fixed on a holder with the use of adhesive carbon tape, and gold-sputtered.

Moreover, in order to confirm the modifications of $\mathrm{KBC}$, the FTIR spectra of all samples were recorded using a Nicolet iS10 FT-IR spectrometer with an ATR configuration. All the spectra were baseline-corrected using the OMNIC software.

Finally, to establish the behaviour of the tested fabrics in contact with water, contact angle (CA) measurements were performed by using a goniometer (OCA25, DataPhysics). All the measurements were done in room temperature using the sessile drop method. The liquid used for these experiments was deionized water (Millipore). Each material was placed in a dedicated holder so that the surface of the material was flat. Then, three separate droplets of water $(2 \mu \mathrm{l})$ were put on the material, and a film was recorded for $5 \mathrm{~min}$. Afterward, for every fifth frame, the contact angle was measured showing the changes of that parameter over time, and the average of three measurements was calculated. As a result, a plot of contact angle versus time was prepared.

Durability of the tested fabrics

The mechanical properties of the materials, i.e., the tensile strength $(\sigma)$, Young's Modulus $(E)$, maximum force $\left(F_{m}\right)$, elongation at maximum force $\left(\varepsilon_{m}\right)$ were determined by the use of a testing machine Inspect Table Blue 5kN (Hegewald\&Peschke, Germany). The samples preparation and procedure of tensile properties testing were performed according to the ISO 13934-1 standard. For this purpose, specimens with $50 \times 200 \mathrm{~mm}$ (width $\times$ length) were prepared. The pre-load force was $2 \mathrm{~N}$, and the test speed was $100 \mathrm{~mm} / \mathrm{min}$. Mechanical parameters were calculated 
by averaging 10 measurements and were presented as the mean \pm standard deviation. Also, the stress-strain curves and tensile parameters of $\mathrm{KBC}$, cHGBC and cotton were investigated (Supplementary MaterialMechanical Testing Section).

Additionally, flame-resistance of the obtained materials was tested. The fabrics obtained from processed kombucha stripes $5 \times 3 \mathrm{~cm}$ were exposed to direct flame accordingly to the standard test for fabrics (ASTM D6413: Vertical Flame Test for Flame Resistance of Textiles). A specimen was suspended in an enclosed chamber and secured. The edge of the fabric was exposed to a controlled flame (gas burner) for $12 \mathrm{~s}$. After flame exposure the afterglow and char length were measured.

Cellulose-based textiles: designing, stitching and testing of the materials

In order to test whether the HGBC material was suitable as fabric for clothing, two pieces of simple wardrobe were made, namely a wristband and a T-shirt. Moreover, it turned out that the obtained fabric was sufficiently durable for machine sewing. Wristbands $(16 \times 2.5 \mathrm{~cm})$ were designed with enlarged surfaces to provide more contact with skin $\left(40 \mathrm{~cm}^{2}\right.$ in total) (see Fig. 6a). In the central part, more material and welts were added to make the bands adaptable to the size of the hand around the wrist. Such a selection of the test element of the small wardrobe item was to imitate elastic wrist bands absorbing sweat like the ones used by tennis players. Another tested element of the wardrobe were $\mathrm{T}$-shirts containing elements of the coated HGBC material sewn into the cotton structure (see Fig. 6b). Thus, cellulose elements were placed on several body areas with various sweating levels according to the literature (Smith and Havenith 2011). The added elements were in contact with abdominal and chest surfaces, which are more sensitive to irritants than the neck and back. These are the areas where the fabric can rub on sensitive elements of the chest/breast (moving freely as it does not cling to the body) and cause unwanted reactions of the body or discomfort.

Finally, both the wristbands and T-shirts were tested on volunteers during the SPECTRA lunar analog simulation (simulation of the astronauts living conditions on an extra-terrestrial space station) in the Lunares habitat in Pila (sealed self-sufficient laboratory/residential modules), Poland, on July 14-19, 2018. Such a test site provided full control over the working and living environment of people who participated in the study. Four individuals voluntarily wore wristbands made of the tested fabric and used them continuously for 2 weeks. Observations of the skin areas covered by the tested pieces of clothing concentrated on discoloration, material pattern and sensitivity and were made daily. Similarly, the $\mathrm{T}$ shirts were tested by the commander of the analog astronaut crew. The comfort of use of the tested materials and general impressions while wearing such clothing were tested after the mission by using a questionnaire from the free online survey tool, Survey Monkey (www.surveymonkey.com).

\section{Results}

Bacterial-derived cellulose preparation and its physicochemical behaviour

As described in the methodology part, the preparation of the final material (HGBC or cHGBC) consisted of several steps. During each step, a significant amount of water is used, which from the industrial point of view is not desirable. That is why water was recovered by using the freeze-drying method at each stage of the synthesis. As a result, the recovery percentage was as follows: 70,80 , and $90 \%$ for the medium, wet cellulose and water used for rinsing and heat treatment, respectively. Moreover, the residue obtained after lyophilization might be further used as a raw source of carbon, e.g., for agricultural applications.

Kombucha-derived cellulose is a complex material comprised of the network of cellulose fibres that still contains bacteria and yeast cells. The surface of such a raw material is shown in Fig. 1.

As it can be seen, the raw material still contains microorganisms embedded in the cellulose fibres. Hence the primary and most important purpose of any treatment of the raw cellulose is to remove these living microbial contaminants, as well as low molecular weight chemical compounds associated with their presence (e.g., sucrose being their nourishment, metabolites produced by the microorganism). This is crucial when the use of such material as fabric is considered, since it allows for eliminating the danger of infecting other surfaces with these organisms. 
Additionally, such treatments allow for removing compounds with an unpleasant smell.

Therefore, initially, we used simple thermal treatment in a water solution. Unfortunately, purified cellulose after drying (KBC) shows properties similar to parchment, i.e., is rigid, easy to tear, and has low mechanical resistance (Supplementary MaterialMechanical Testing Section). Thus, in order to improve the properties of the obtained materials, supplementing the cellulose's network with a chemical compound (i.e., glycerol) was proposed, which additionally should provide water retention. As a result, a polymer hydrogel (HydroGel Bacterial Cellulose, HGBC) was obtained, in which both water and glycerol provided lubrication at the molecular level. This treatment significantly improved for example the mechanical properties of the material.

Furthermore, such material surface could be additionally sealed with stearic acid. The proposed manufacturing method resembles the one used to obtain "wax canvas." It is a simple and ecological way of improvement of properties of natural fabrics. Such a wax-like additive which is spread on and adsorbed by the surface reduces the unwanted effects associated with a short-time contact of the material with water. However, it did not affect the swelling of the fabric during long-term interaction, as explained below. The microphotographs of the uncoated and coated HGBC fabrics are shown in Fig. 2.

As it can be seen, in case of the uncoated material, chaotically arranged cellulose fibres were still present (Fig. 2a). On the other hand, when the material was coated with stearic acid (Fig. 2b), a much more even surface was obtained. The acid filled the spaces between the fibres, providing a much smoother fabric.
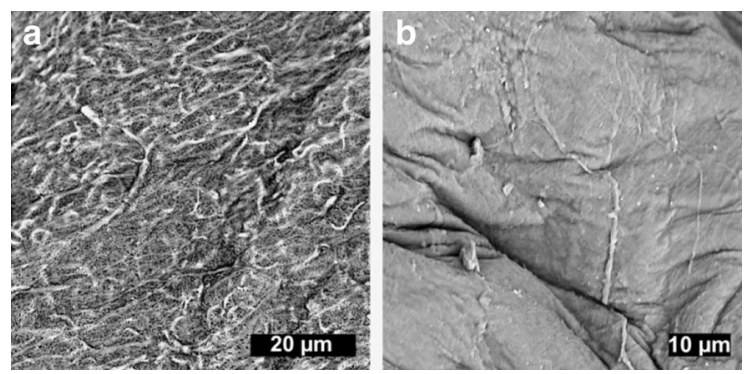

Fig. 2 SEM microphotographs of the uncoated (a) and coated (b) HGBC fabrics
To further confirm the changes in the material composition after the treatments, the IR spectrum was recorded. The results can be seen in Fig. 3.

As it can be seen from the IR spectra, when raw cellulose is considered (continued line), peaks corresponding only to cellulose and the residual contaminants from the carboxylic acids (presence of a weak peak at $1700 \mathrm{~cm}^{-1}$ corresponding to $\mathrm{C}=\mathrm{O}$ vibrations) were visible. When glycerin-treated samples are considered, the spectrum was similar to that for the raw material (dashed line). However, the peak at $1700 \mathrm{~cm}^{-1}$ was less visible due to the successful removal of carboxylic acids. Moreover, three characteristic peaks of cellulose bands appeared in the range of 990 to $1050 \mathrm{~cm}^{-1}$ (from C-O vibrations). It should be emphasized that the presence of glycerin cannot be established from the IR spectra since the peaks for cellulose and glycerin overlap (Higgins et al. 1961). Finally, when stearic acid-treated fabrics are considered (dotted line), the above-mentioned characteristic structure of the bands $\left(990-1050 \mathrm{~cm}^{-1}\right)$ from cellulose $\mathrm{C}-\mathrm{O}$ vibrations was preserved. However, new strong bands characteristic of stearic acid at 2850 and $2920 \mathrm{~cm}^{-1}$ from $\mathrm{C}-\mathrm{H}$ vibrations, and at $1700 \mathrm{~cm}^{-1}$ from $\mathrm{C}=\mathrm{O}$ vibrations appeared and were separated (Lee and Kim 1998). This proved the presence of stearic acid in the final fabric.

The behaviour of every material, especially those for clothes, in contact with liquids is of a great importance. The wettability of such material defines its potential applicability, not to mention the wear comfort. Therefore, as it was mentioned before, the wettability tests were performed on dried raw cellulose (KBC), as well as the uncoated and coated HGBC

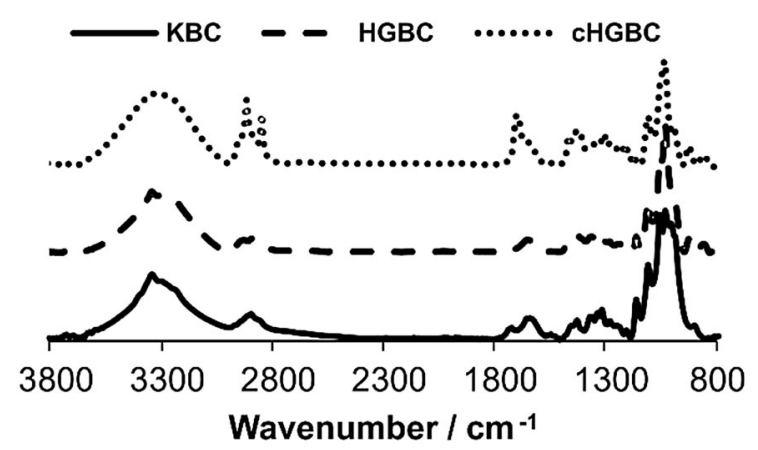

Fig. 3 IR spectra of the kombucha-derived cellulose before and after treatments with glycerol (HGBC) and stearic acid (cHGBC) 
fabrics. The most important results for measurements of the contact angle (CA) are shown in the table below (Table 1). Detailed plots of the CA changes in time can be found in the Supplementary Material-Contact Angle Section.

Based on the presented results it may be suggested that stearic acid-coating did not affect the capacity of the processed cellulose to swell in the presence of water. However, the change in the affinity of the surface to water prior to the swelling process might be observed (a significantly higher initial CA). Such behaviour may be significant in the case of short-term contact of the material with water, such as the exposure of clothes to sweat during their daily use. Swelling of the fabric provides the possibility of binding sweat by the material during its use, what may be beneficial from the practical point of view. Therefore, the swelling coefficient was calculated on the bases of previous reports by Kaminski et al. (2008), according to Eq. 1.

$W=\frac{\left(m_{1}-m_{0}\right)}{m_{0}} \times 100 \%$

where $\mathrm{m}_{0}$ weight of the material before immersion in water $[\mathrm{g}] ; \mathrm{m}_{1}$ weight of the swollen material $[\mathrm{g}]$;

The results are shown in the table below (Table 2).

As indicated by data in Table 2, the swelling capacity which is expressed as the swelling coefficient, depends on the type and quantity of water retention agents present in the fabric. This allows us for controlling the properties of the fabric depending on the application. When glycerol-treated materials, i.e., $6 \mathrm{wt} \%$ and $12 \mathrm{wt} \%$ glycerol HGBC are considered, a super-sorbent material that can absorb sweat (or other physiological fluids) is obtained. Water absorption lasts much longer, which is characteristic of such types of materials. On the other hand, the presence of chitosan limits swelling considerably, what is indicated by saturation of the swelling capacity in time. Therefore, it may be stated that by simply changing the modifier (or its concentration), the swelling properties of $\mathrm{BC}$ material may be altered.

Mechanical durability of the coated HGBC fabrics

For designing apparel uses, the knowledge about the tensile properties of materials is essential. The strength, elasticity, and elongation are the key factors governing the textile/material performance in use.

According to the tensile test results, cHGBC sheets were characterized by the Young's modulus, tensile strength, maximum force, and elongation at maximum force (Fig. 4). As the reference, KBC sheets were tested. The variations between the results of particular tensile parameters in the tested samples, represented by the standard deviation values, were strongly correlated with the thickness and homogeneity of the samples.

The results demonstrated that the cHGBC samples exhibited considerably high values of maximum tensile strength combined with enhanced elasticity when compared to KBC. Such values are beneficial from the application point of view since the elasticity of textiles is of a great importance. Also, the maximum force and elongation at the maximum force values were improved for $\mathrm{CHGBC}$. It is worth noting that the changes in cHGBC in comparison with $\mathrm{KBC}$ were statistically significant. Typical characteristic stressstrain curves for HGBC versus $\mathrm{KBC}$ are shown in Fig. S2 (Supplementary Data). The stress-strain curves were used for the characterization of the samples under tension. As can be seen, HGBC showed a remarkable improvement of both strain (over eightfold) and stress (over twofold) when compared to the raw KBC. This linearity occurred until the first tear appeared (directed perpendicularly to the force). Fortunately, regardless of the progressive tearing process, cHGBC sheets remained able to bear the loads until the complete rupture of the sample. It is clear that the proposed procedure of hydrogel bacterial cellulose manufacturing was advantageous from the
Table 1 Results of CA measurements of the obtained cellulose materials

\begin{tabular}{lll}
\hline Type of material & Contact angle $(\mathrm{CA})$ values ${ }^{\circ}$ & \\
\cline { 2 - 3 } & Immediately after administration & After 5 min \\
\hline KBC & $58.50 \pm 0.95$ & $50.50 \pm 1.15$ \\
HGBC & $56.70 \pm 2.20$ & $\sim 5$ \\
coated HGBC & $69.60 \pm 3.90$ & $\sim 5$ \\
\hline
\end{tabular}


Table 2 Changes in the coefficient of swelling (W) in time for the raw and modified cellulose materials

\begin{tabular}{|c|c|c|c|}
\hline \multirow[t]{2}{*}{ Type of material } & \multicolumn{2}{|c|}{$\begin{array}{l}\text { Coefficients of swelling (W) corresponding to the } \\
\text { immersion time }(\%)\end{array}$} & \multirow[t]{2}{*}{ Increment of $\mathrm{W}$ from 5 to $15 \mathrm{~min} / \%$} \\
\hline & $5 \min$ & $15 \mathrm{~min}$ & \\
\hline $\mathrm{KBC}$ & $0.60 \pm 0.14$ & $0.60 \pm 0.14$ & 0 \\
\hline Coated HGBC 6 wt $\%$ glycerol & $1.88 \pm 0.14$ & $2.37 \pm 0.15$ & 26 \\
\hline HGBC 12 wt $\%$ glycerol* & $0.69 \pm 0.08$ & $0.83 \pm 0.19$ & 20 \\
\hline HGBC 6 wt $\%$ glycerol and chitosan & $0.75 \pm 0.02$ & $0.75 \pm 0.02$ & 0 \\
\hline
\end{tabular}

*The material is unstable and the leakage of water containing glycerol to the solution in which the swelling was measured was visible

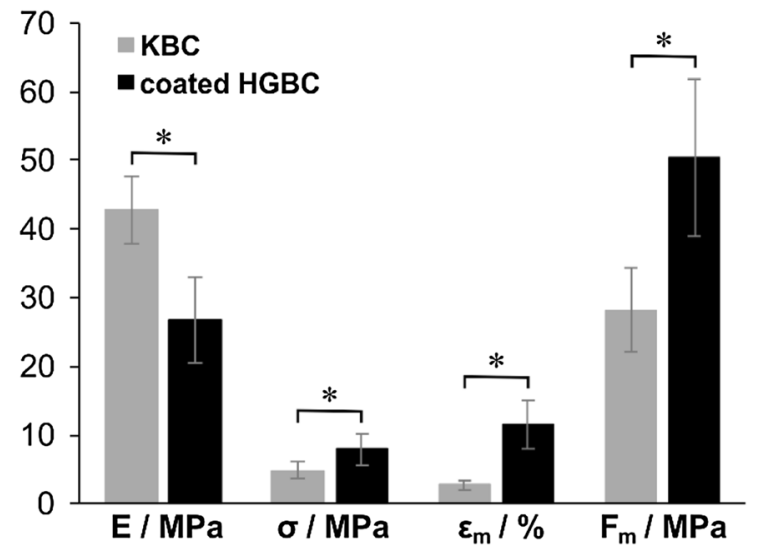

Fig. 4 The mechanical properties of materials investigated during the tensile test. E-Young's modulus, $\sigma$-tensile strength, $\varepsilon_{\mathrm{m}}$-elongation at maximum force, $\mathrm{F}_{\mathrm{m}}$ maximum force. Statistically significant differences $(p<0.05)$ between mechanical parameters of KBC and coated HGBC are indicated by the connector and asterisk $(*)$

viewpoint of the mechanical properties. To be precise, the supplementation of raw cellulose (KBC) to obtain stable hydrogel (HGBC) resulted in a significant improvement of material elasticity, tensile strength, and elongation, what is especially important when its textile applicability is considered.

In order to place the results in a wider context, we compared the mechanical properties of both types of bacteria cellulose with those for the $100 \%$ cotton textile (T-shirt) (Table S1). However, it should be emphasized that such a comparison is not easy, since the fibre structure of both types of materials is extremely different. It should be stressed that there are many factors that could exert a significant impact on the mechanical behaviour of a bacterial cellulose material, i.e., the manufacturing of the materials (incubation, drying route, additives purification), homogeneity of the final sheets, specimens preparation, finally the mechanical testing parameters (uniaxial or biaxial tension, dry or wet samples, etc.). Moreover, not all experimental details are usually given, thus the straightforward comparison of the mechanical properties is additionally difficult. For example, the tensile strength of the bacterial cellulose reported by George et al. (2005) was about $43 \mathrm{MPa}$, while Gea et al. (2011) reported the tensile strength ranging from 88.9 to $207.0 \mathrm{MPa}$. Also, a wide disparity in the values of the Young's modulus was shown, with the range from 9 to $30 \mathrm{GPa}$ (Ashjaran et al. 2013; McKenna et al. 2009). Therefore, it is safe to assume that the proposed materials show similar or higher values of tensile properties as compared to the data presented in the literature when HGBC textile fabrics are considered (Mohite and Patil 2014; Wood et al. 2015). What is more, Domskiene et al. (2019) reported manufacturing of kombucha-derived $\mathrm{BC}$ and its drying at various temperatures $\left(25-75^{\circ} \mathrm{C}\right)$ (Domskiene et al. 2019). They also tested the strength and deformability for both wet and dried KBC sheets. The results showed a rapid drop of elongation and an increase of tensile strength and Young's modulus after drying; however, these parameters decreased with increasing drying temperature values. Our results stay in good correlation with those results, i.e., dried KBC was stiff and ruptured at low elongation. Modification of the KBC structure by introduction of a moisturizer (glycerol) led to an increase in material strength $(\sigma$ and $\mathrm{F}_{\mathrm{m}}$ ) on the one hand, and elasticity (enhanced $\varepsilon_{\mathrm{m}}$ and decreased E) of the material on the other.

Moreover, further advanced investigations are needed to determine the properties of the proposed 
materials. For example, water absorption, rate of polymerization, and crystallinity, which may affect their mechanical properties and functionality will be tested in the future. What is more, further optimization of the manufacturing method is also needed in order to optimize the uniformity of the material structure and thickness, as these parameters directly affect the mechanical performance of the material. Nonetheless, the materials proposed here are characterized by a positive correlation of the elasticity and mechanical strength for the textile fabric application.

Another important parameter when it comes to such materials is their flame resistance. Therefore, the cHGBC material was exposed directly to the flame under controllable conditions. Fabric samples ( $\sim 6 \mathrm{~mm}$ thin) before and after exposition to flame are shown in Fig. 5. The material was locally scorched and blackened in response to flame. However, flame was not spreading across the sample due to the presence of water within the hydrogel structure of the fabric. The visible flame disappeared after withdrawal of the external source of fire. No visible glow was seen afterward, and after $10 \mathrm{~min}$, the temperature of the fabric dropped to room temperature. Moreover, the size of the blackened fragment coincided with the width of the applied flame. Neither dripping of the material, nor visible sparks were observed.

Cellulose-based clothes: designing, stitching and testing of the materials

As it was mentioned before, $\mathrm{cHGBC}$ was used to create two pieces of clothing - a wristband and a T-shirt. The photographs of the designed and sewed clothes are shown in Fig. 6.

The wristbands and T-shirts were tested by the volunteers during the lunar analog simulation in the Lunares habitat in Pila, Poland. They were participating in various physical activities, exercising, working, and resting. The volunteers constantly wore

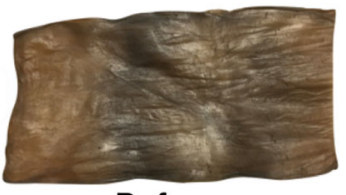

Before

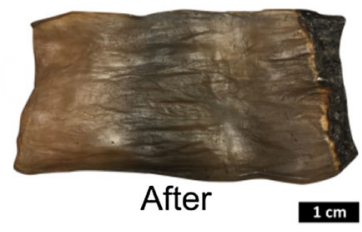

Fig. 5 Thin fragments of the coated material before and after exposure to flame

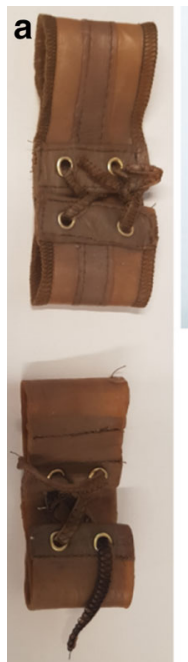

b

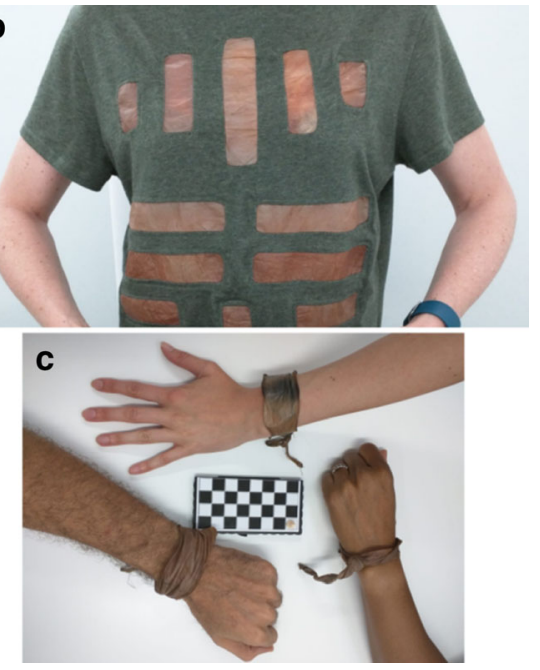

Fig. 6 Photographs of the finished articles of clothing: a wristband, b T-shirt with sewn in cellulose-based coated fabric. c Wristband after 2 weeks of use

wristbands for a fortnight. Therefore, the bands were additionally exposed to water during, e.g., hygieneassociated activities and daily routine. Moreover, the wristbands were washed and survived the process without damage. After 2 weeks, the fabric partially lost its flexibility. However, contrary to the raw dry bacterial cellulose, the loss did not lead to material tearing. Undesirable effects were limited only to the folding of the fabric and local discolorations caused by e.g., dirt accumulation, which is typical for long-term use of clothes. The wristbands after 2-weeks of use are shown in Fig. 6c. Additionally, the changes in the material in time are also illustrated in Supplementary Material (Fig. S3). Moreover, the SEM microphotographs of the used material are shown in Fig. 7a, b.

As it can be seen from the SEM images, after a 2-week use of the fabric, the material was not re-
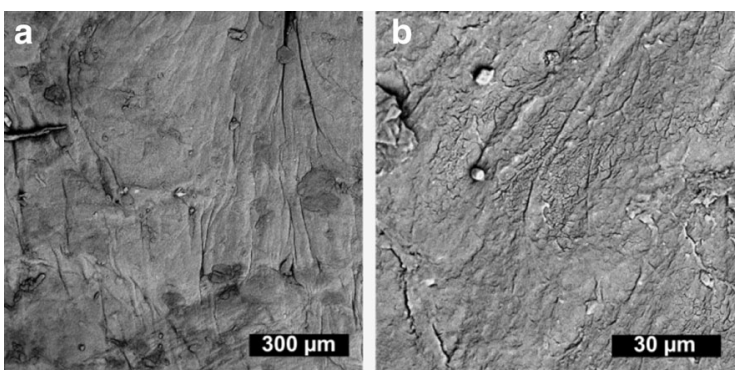

Fig. 7 SEM microphotographs of the inner surface of the used wristbands (a, b) 
colonized by the native organisms (from the initial bioreactor synthesis) or by human microflora. Lack of microorganisms suggests that the applied production process ensures both complete sterilization of the fabric and lack of stimulation for other microorganisms to grow.

An analogous effect can be obtained when using more complex cellulose treatment methods, e.g., alkali treatment (Dickerman and Starr 1951; Junka et al. 2017). However, as described in the Introduction, such procedures require significant amounts of water, which is not beneficial from the ecological point of view.

Moreover, the microstructure of the fabric did not change after an enhanced contact with water and sweat as confirmed by photos.

In case of any article of clothing, the user's comfort is of a great importance. That is why participants wearing the wristbands were asked to give feedback on the subject. Details of the questionnaire replies can be found in the Supplementary Material-Questionnaire Section. When addressing such parameters as comfort, visual appearance, softness, skin discoloration/irritation, smell, flexibility and sweat absorption, the average answers indicated neutral or good opinions.

One of the crucial parameters that we were interested in was the skin discoloration/irritation (photographic documentation not shown). The respondents indicated no such severe reactions, which is a satisfactory result proving that the proposed material may be further used as fabric for clothes.

\section{Conclusions}

To conclude, the results obtained in the present study confirm the concept of an environmentally-friendly technology allowing for obtaining textiles based on bacterial cellulose originating from a kombuchaforming microorganism conglomerate, and for processing such fabric. The use of bacterial cellulose in this way is not new; however, the processing technology is. The concept of supplementing raw cellulose with glycerol and transforming it into a stable hydrogel dramatically improved the mechanical properties of the finished fabric, which confirmed the initial assumptions. Moreover, we were able to prove that by simply changing the modifying compound, the swelling properties of the material also changed. This is especially important when the application of such material is considered.

The presented concept showed that kombucha bioreactors might produce bacterial cellulose from completely renewable and reusable sources and according to the principles of waste-free technologies. Moreover, the procedure of synthesising the almost ready-to-use fabric from the raw material was also demonstrated. Such a fabric had relatively good mechanical properties and the SEM microphotographs allowed for fully characterizing the material at the sub-micro level at every stage of its production and processing. Finally, fire resistance tests proved the inflammability of the fabric.

When cloth materials are considered, the comfort of use is equally important. That is why we conducted field tests of the material with the participation of volunteers who wore HGBC wristbands and T-shirts containing sewn in pieces of the new fabric. The reported feedback allowed for forming the opinion that HydroGel Bacterial Cellulose fabric may be a viable alternative for the currently used synthetic materials.

Such a holistic approach to the research goals makes the obtained results a strong argument that the presented work proves as viable the concept of the synthesis procedure being a green and waste-free technology that will open entirely new possibilities for the industry.

Acknowledgments The SEM imaging was partially performed in the Laboratory of Field Emission Scanning Electron Microscopy and Microanalysis at the Institute of Geological Sciences, Jagiellonian University, Poland. The items of clothing were tested during the analog lunar mission SPECTRA in the Lunares habitat in Pila, Poland, established by Space Garden Company.

\section{Compliance with ethical standards}

Conflict of interest The authors declare that they have no conflict of interest.

Ethical approval All experiences involving human participants were approved by the Bioethics Commission at the Medical University in Poznan. Consent based on Resolution No. 685/17 published on July 6, 2017.

Open Access This article is licensed under a Creative Commons Attribution 4.0 International License, which permits use, sharing, adaptation, distribution and reproduction in any medium or format, as long as you give appropriate credit to the 
original author(s) and the source, provide a link to the Creative Commons licence, and indicate if changes were made. The images or other third party material in this article are included in the article's Creative Commons licence, unless indicated otherwise in a credit line to the material. If material is not included in the article's Creative Commons licence and your intended use is not permitted by statutory regulation or exceeds the permitted use, you will need to obtain permission directly from the copyright holder. To view a copy of this licence, visit http://creativecommons.org/licenses/by/4.0/.

\section{References}

Abitbol T, Rivkin A, Cao Y, Nevo Y, Abraham E, Ben-Shalom T, Lapidot S, Shoseyov O (2016) Nanocellulose, a tiny fiber with huge applications. Curr Opin Biotech 39:76-88

Ahmed T, Shahid M, Azeem F, Rasul I, Shah AA, Noman M, Hameed A, Manzoor N, Manzoor I, Muhammad S (2018) Biodegradation of plastics: current scenario and future prospects. Environ Sci Pollut R 25:7287-7298

Akkus A, Tyler R, Schiraldi D, Roperto R, Faddaul F, Teich S (2017) Effect of polyethylene oxide on the thermal degradation of cellulose biofilm: low cost material for soft tissue repair in dentistry. J Clin Exp Dent 9:e875-e878

Andrade FK, Silva JP, Carvalho M, Castanheira EM, Soares R, Gama M (2011) Studies on the hemocompatibility of bacterial cellulose. J Biomed Mater Res A 98:554-566

Araújo S, da Silva FM, Gouveia IC (2015) The role of technology towards a new bacterial-cellulose-based material for fashion design. J Ind Intell Inf 3:168-172

Ashjaran A, Yazdanshenas ME, Rashidi A, Khajavi R, Rezaee A (2013) Overview of bio nanofabric from bacterial cellulose. J Text Inst 104:121-131

Azeredo HMC, Barud H, Farinas CS, Vasconcellos VM, Claro AM (2019) Bacterial cellulose as a raw material for food and food packaging applications. Front Sustain Food Syst $3: 1-14$

Bandyopadhyay S, Saha N, Saha P (2018) Characterization of bacterial cellulose produced using media containing waste apple juice. Appl Biochem Biotechnol 54:649-657

Basta AH, El-Saied H (2009) Performance of improved bacterial cellulose application in the production of functional paper. J Appl Microbiol 107:2098-2107

Béguin P, Aubert JP (1994) The biological degradation of cellulose. FEMS Microbiol Rev 13:25-58

Blanc PJ (1996) Characterization of the tea fungus metabolites. Biotechnol Lett 18:139-142

Brown AJ (1886) An acetic ferment which forms cellulose. J Chem Soc Trans 49:432-439

Campano C, Balea Martin A, Blanco A, Negro C (2015) Enhancement of the fermentation process and properties of bacterial cellulose: a review. Cellulose 23:57-91

Carney Almroth BM, Åström L, Roslund S, Petersson H, Johansson M, Persson NK (2018) Quantifying shedding of synthetic fibers from textiles; a source of microplastics released into the environment. Environ Sci Pollut R 25:1191-1199
Chissoe WF, Vezey EL, Skvarla JJ (1994) Hexamethyldisilazane as a drying agent for pollen scanning electron microscopy. Biotech Histochem 69:192-198

Codgell C (2011) From BioArt to BioDesign. Am Art 25:25-29

Costa AFS, Almeida FCG, Vinhas GM, Sarubbo LA (2017) Production of bacterial cellulose by Gluconoacetobacter hansenii using corn steep liquor as nutrient sources. Front Microbiol 8:1-12

Dickerman JM, Starr TJ (1951) A medium for the isolation of pure cultures of cellulolytic bacteria. J Bacteriol 62:133-134

Dima SO, Panaitescu DM, Orban C et al (2017) Bacterial nanocellulose from side-streams of kombucha beverages production: preparation and physical-chemical properties. Polymers 9:374(1)-374(2)

Domskiene J, Sederaviciute F, Simonaityte J (2019) Kombucha bacterial cellulose for sustainable fashion. Int J Cloth Sci Tech. https://doi.org/10.1108/IJCST-02-2019-0010

El-Saied H, Basta AH, Gobran RH (2004) Research progress in friendly environmental technology for the production of cellulose products (bacterial cellulose and its application). Polym-Plast Technol Eng 43:797-820

Fischer ER, Hansen BT, Nair V, Hoyt FH, Dorward DW (2012) Scanning electron microscopy. Curr Protoc Microbiol 25:2B.2.1-2B.2.47

Fontana JD, Souza AM, Fontana CK, Toriani IL, Moreschi JC, Gallotti BJ, de Souza SJ, Narcisco GP, Bichara JA, Farah LF (1990) Acetobacter cellulose pellicle as a temporary skin substitute. Appl Biochem Biotechnol 24-25:253-264

Gago J, Carretero O, Filgueiras AV, Viñas L (2018) Synthetic microfibers in the marine environment: a review on their occurrence in seawater and sediments. Mar Pollut Bull 127:365-376

Gao M, Li J, Bao Z, Hu M, Nian R, Feng D, An D, Li X, Xian M, Zhang H (2019) A natural in situ fabrication method of functional bacterial cellulose using a microorganism. Nat Commun 10:437. https://doi.org/10.1038/s41467-01807879-3

Gea S, Reynolds CT, Roohpour N, Wirjosentono B, Soykeabkaew N, Bilotti E, Peijs T (2011) Investigation into the structural, morphological, mechanical and thermal behaviour of bacterial cellulose after a two-step purification process. Bioresour Technol 102:9105-9110

George J, Ramana KV, Sabapathy SN, Bawa AS (2005) Physico-mechanical properties of chemically treated bacterial (acetobacter xylinum) cellulose membrane. World J Microbiol Biotechnol 21:1323-1327

Habibi Y, Lucia LA, Rojas OJ (2010) Cellulose nanocrystals: chemistry, self-assembly, and applications. Chem Rev 110:3479-3500

Higgins HG, Stewart CM, Harrington KJ (1961) Infrared spectra of cellulose and related polysaccharides. J Polym Sci Part A 51:59-84

Hioki N, Hori Y, Watanabe K, Morinaga Y, Yoshinaga F, Hibino Y, Ogura T (1995) Bacterial cellulose; as a new material for papermaking. Kami-Gikyo-Shi 49:82-87

Jayabalan R, Malbaša RV, Lončar ES, Vitas JS, Sathishkumar M (2014) A review on kombucha tea: microbiology, composition, fermentation, beneficial effects, toxicity, and tea fungus. Compr Rev Food Sci Food Saf 13:538-550 
Junka A, Fijałkowski K, Ząbek A et al (2017) Correlation between type of alkali rinsing, cytotoxicity of bionanocellulose and presence of metabolites within cellulose membranes. Carbohydr Polym 157:371-379

Kamiński K, Zazakowny K, Szczubiałka K, Nowakowska M (2008) pH-sensitive genipin cross-linked chitosan microspheres for heparin removal. Biomacromol 9:3127-3132

Keshk SMAS (2014) Bacterial cellulose production and its industrial applications. $\mathrm{J}$ Bioprocess Biotech 4:1000150(1)-1000150(10)

Kombucha Couture (2019) http://www.kombuchacouture.com/. Accessed 22 July 2019

Kulkarni PK, Anil Dixit S, Singh UB (2012) Evaluation of bacterial cellulose produced from Acetobacter xylinum as pharmaceutical excipient. Am J Drug Discov Dev 2:72-86

Kuwana Y (1997) Production and new function of Nata de Coco. Cell Commun 4:25-28

Lee S (2019) Biocouture. Launch Fabric (2019) https://www. launch.org/innovators/suzanne-lee/. Accessed 22 July 2019

Lee SJ, Kim K (1998) Diffuse reflectance infrared spectra of stearic acid self-assembled on fine silver particles. Vib Spectrosc 18:187-201

Li L, Frey M, Browning KJ (2010) Biodegradability study on cotton and polyester fabrics. J Eng Fiber Fabr 5:42-53

Lima HLS, Nascimento ES, Andrade FK, Brigida AIS, Borges MF, Cassales AR, Muniz CR, de Souza Filho MSM, Morais JPS, de Rosa MF (2017) Bacterial cellulose production by Komagataeibacter hansenii ATCC 23769 using sisal juice: an agroindustry waste. Braz J Chem Eng 34:671-680

Marsh AJ, O'Sullivan O, Hill C, Ross RP, Cotter PD (2014) Sequence-based analysis of the bacterial and fungal compositions of multiple kombucha (tea fungus) samples. Food Microbiol 38:171-178

Matthysse AG, Thomas DL, White AR (1995) Mechanism of cellulose synthesis in Agrobacterium tumefaciens. J Bacteriology 177:1076-1081

McKenna BA, Mikkelsen D, Wehr JB, Gidley MJ, Menzies NW (2009) Mechanical and structural properties of native and alkali-treated bacterial cellulose produced by Gluconacetobacter xylinus strain ATCC 53524. Cellulose 16:1047-1055

Mohite BV, Patil SV (2014) Physical, structural, mechanical and thermal characterization of bacterial cellulose by $G$. hansenii NCIM 2529. Carbohydr Polym 106:132-141

$\mathrm{Ng}$ A (2017) Grown microbial 3D fiber art, Ava: fusion of traditional art with technology. In: Conference paper at proceedings of the 2017 ACM international symposium on wearable computers, Maui, Hawaii, pp 209-214

Ng FMC, Wang PW (2016) Natural self-grown fashion from bacterial cellulose: a paradigm shift design approach in fashion creation. Des J 19:837-855

Nguyen NK, Nguyen PB, Nguyen HT, Le PH (2015) Screening the optimal ratio of symbiosis between isolated yeast and acetic acid bacteria strain from traditional kombucha for high-level production of glucuronic acid. Lwt-Food Sci Technol 64:1149-1155

Podolich O, Zaets I, Kukharenko O et al (2017) Kombucha multimicrobial community under simulated spaceflight and martian conditions. Astrobiology 17:459-469

Podolich O, Kukharenko O, Haidak A et al (2019) Multimicrobial kombucha culture tolerates Mars-like conditions simulated on low Earth orbit. Astrobiology 19:183-196

Reiniati I, Hrymak AN, Margaritis A (2017) Recent developments in the production and applications of bacterial cellulose fibers and nanocrystals. Crit Rev Biotechnol 37:510-524

Salmeia KA, Jovic M, Ragaisiene A, Rukuiziene Z, Milasius R, Mikucioniene D, Gaan S (2016) Flammability of cellulosebased fibers and the effect of structure of phosphorus compounds on their flame retardancy. Polymers 8:293(1)293(15)

Sederavičiūtė F, Bekampienė P, Domskienè J (2019) Effect of pretreatment procedure on properties of Kombucha fermented bacterial cellulose membrane. Polym Test 78:105941(1)-105941(7)

Smith CJ, Havenith G (2011) Body mapping of sweating patterns in male athletes in mild exercise-induced hyperthermia. Eur J Appl Physiol 111:1391-1404

Venter O, Sanderson EW, Magrach A et al (2016) Sixteen years of change in the global terrestrial human footprint and implications for biodiversity conservation. Nat Commun 7:12558(1)-12558(11)

Wang HY, Qian H, Yao WR (2011) Melanoidins produced by the mail lard reaction: structure and biological activity. Food Chem 128:573-584

Wood D, Liu H, Salusso C (2015) Production and characterization of bacterial cellulose fabrics. Presented in part at Int Text Appar Assoc Annu Conf Proc, Santa Fe, New Mexico, November, 2015. https://lib.dr.iastate.edu/itaa proceedings/2015/posters/143. Accessed September 2018

Publisher's Note Springer Nature remains neutral with regard to jurisdictional claims in published maps and institutional affiliations. 